\title{
Improved survival in patients with FDG-PET/CT-based radiotherapy treatment planning for squamous cell anal cancer
}

\author{
R. LOHYNSKA ${ }^{1,4, *}$, E. MAZANA ${ }^{1}$, A. NOVAKOVA-JIRESOVA ${ }^{1}$, M. JIRKOVSKA ${ }^{2}$, A. NYDLOVA ${ }^{2}$, T. VESELSKY ${ }^{3}$, B. MALINOVA $^{2}$, T. BUCHLER $^{1}$, \\ H. STANKUSOVA ${ }^{2}$
}

${ }^{1}$ Department of Oncology, First Faculty of Medicine of Charles University and Thomayer Hospital Prague, Czech Republic; ${ }^{2}$ Department of Oncology, Second Faculty of Medicine of Charles University and Motol Hospital, Prague, Czech Republic; ${ }^{3}$ Department of Medical Physics, Motol Hospital, Prague, Czech Republic; ${ }^{4}$ First Faculty of Medicine of Charles University and Na Bulovce Hospital Prague, Institute of Radiation Oncology, Czech Republic

${ }^{*}$ Correspondence: radka.lohynska@ftn.cz

Received December 29, 2019 / Accepted February 6, 2020

\begin{abstract}
The aim of this retrospective analysis was to evaluate the impact of FDG-PET/CT-based target volume definition on locoregional control and survival, compared to conventional CT-based target volume definition and dose prescription. One hundred and twenty-two patients with squamous cell anal cancer were treated with curative radiotherapy (RT) alone (27\%) or with RT with concurrent chemotherapy (73\%) and analyzed. Forty-six percent had the early disease (stage I+II) and $54 \%$ were stage III. FDG-PET/CT-based staging was performed in $21 \%$ of the patients. The mean follow-up time was 60 months. Other risk factors affecting survival were investigated. According to initial staging in both groups (FDG-PET/ CT and conventional CT) were $10 \%$ of stage IV disease, and they were excluded from radical radiotherapy and treated with palliative intent. Ninety-two percent of the patients achieved complete remission. Significant favorable factors in univariate analysis associated with disease-free survival (DFS) were PET/CT staging, T1/2 and N0 stage, and clinical stage I and II. Locoregional control (LRC) correlated with the T1/2 stage and initial performance status (PS) 0 . There were no significant factors affecting overall survival (neither in univariate nor multivariate analysis). In multivariate analysis, the factor associated with better DFS was PET/CT staging and for LRC, PS 0 and concomitant chemoradiation. Acute toxicity was increased in the concurrent chemo-radiotherapy group. Two-, five- and ten-year overall survival rates were $83 \%$, $69 \%$, and $60 \%$; disease-free survival rates were $76 \%, 73 \%, 73 \%$; local control rates were $91 \%, 90 \%$, and $90 \%$ and colostomy-free survival was $89 \%, 86 \%$, and $81 \%$, respectively. PET/CT staging allowed targeted dose escalation to the primary tumor and nodal metastases while decreasing dose to uninvolved regions, resulting in significantly improved DFS without compromising locoregional control.
\end{abstract}

Key words: anal carcinoma, PET/CT, survival, radiotherapy, chemotherapy, prognostic factors

Squamous cell carcinoma is the most common type of anal cancer, with rising incidence but a stable mortality rate over the past 20 years [1]. Improved treatment outcomes are achieved due to diagnostic and therapeutic advances based on a multidisciplinary approach. Surgical resection alone (with $5 \mathrm{~mm}$ safety margin) is appropriate in Tis lesions and small perianal cancers (T1 N0 M0 G1 tumors). The majority of cases are diagnosed in advanced stages requiring curative radiotherapy (RT). The Radiation Therapy Oncology Group (RTOG) 98-11 [2], ACT II [3], ACCORD 3 [4], and other trials $[5,6]$ led to an adoption of concurrent chemoradiation as the standard treatment [7-9]. Salvage surgery has been reserved for non-responders or local recurrence. Chemotherapy alone is applied in metastatic or recurrent inoperable disease.
Achieving local control is a major predictor of treatment outcome. Different RT protocols are associated with varying levels of acute and late toxicity affecting the quality of life. The introduction of intensity modulated RT (IMRT) significantly reduced these toxicities $[10,11]$ and minimized treatment breaks. A strong emphasis has been placed on accurate gross tumor volume (GTV) definition. GTV is defined based on clinical findings (DRE) and tumor imaging by endoscopic and radiological methods including CT and MRI. Elective lymph node CTV delineation is based on well-defined guidelines [12]. Margin definition depends on motion control and set up variations among site protocols.

Recently, the role of 18-fluorodeoxyglucose positron emission tomography (PET) with computed tomography $(\mathrm{CT})$ in clinical staging has been evaluated $[13,14]$. 
PET/CT led to a change in the clinical stage in $17-24 \%$ patients compared to CT alone [15-17]. This necessitated radiation plan modification in up to one-fourth of patients $[18,19]$. Follow-up after anal cancer treatment remains based on individual disease extent [20]. Complete response on PET/CT three months after chemoradiotherapy has been associated with prolonged survival [21,22].

The aim of this retrospective study was to evaluate the clinical impact of PET/CT based radiotherapy planning in patients with squamous cell anal cancer and to assess its influence on disease-free survival, locoregional control, and overall survival.

\section{Patients and methods}

Patients. The cohort included 122 patients treated with curative intent for squamous cell anal carcinoma between 1998 and 2018 were retrospectively evaluated. 73\% of patients were treated in combination with chemotherapy. The median age at the time of diagnosis was 61 years (range $30-88$ years). The majority of patients were females $(80 \%)$. Clinical stage I was present in $16 \%$, stage II in $30 \%$, and stage III in $54 \%$ of patients. $50 \%$ of all patients were smokers. All patients in the present cohort were p16-positive. No routine HIV testing was performed. The mean follow-up time was
60 months. Patient characteristics are shown in Table 1. The median waiting time from biopsy to RT start was 57 days. The median RT duration (external therapy including brachytherapy) was 53 days. The cut-off date for follow-up analysis was July $15^{\text {th }}, 2019$.

All patients underwent physical examination with digital rectal exploration (DRE) and endoscopic exam (anoscopy, rectoscopy, or colonoscopy). Conventional imaging consisted of abdominal and pelvic CT scan, chest X-ray, and transrectal or inguinal ultrasound or pelvic MRI. Twenty-six patients (21\%) treated from 2014 onwards were staged with 18FDG - PET/CT and we have used PET/CT for radiotherapy planning in radically-treated patients. Disease extent was retrospectively restaged according to the $8^{\text {th }}$ edition of TNM classification (International Union against Cancer Classification staging system UICC 2017).

During the whole period, there were 134 patients diagnosed with anal cancer and after initial imaging staging, $10 \%$ was excluded from curative treatment in both groups. In the group of all PET/CT staging, 3 patients $(10 \%)$ were excluded and treated with palliative intent due to a diagnosis of distant metastases. In the conventional staging group, 11 patients $(10 \%)$ were excluded due to the metastatic disease (9 patients) or poor performance status or advanced age (2 patients). PET/CT tailored treatment was used for the GTV

Table 1. Patients and treatment characteristics (Chi-square test).

\begin{tabular}{|c|c|c|c|c|c|}
\hline Variable & Group & All & Conventional staging & PET staging & p-value \\
\hline Mean age (range), years & & $61(30-88)$ & $61(30-88)$ & $63(30-81)$ & 0.486 \\
\hline WHO performance status, $\mathrm{n}(\%)$ & $\begin{array}{l}0 \\
1 \\
\geq 2\end{array}$ & $\begin{array}{c}47(62) \\
26(34) \\
3(4)\end{array}$ & $\begin{array}{c}30(58) \\
19(37) \\
3(5)\end{array}$ & $\begin{array}{l}17(71) \\
7(29) \\
0(0)\end{array}$ & 0.723 \\
\hline Gender, n (\%) & $\begin{array}{l}\text { Female } \\
\text { Male }\end{array}$ & $\begin{array}{l}98(80) \\
24(20)\end{array}$ & $\begin{array}{l}74(77) \\
22(23)\end{array}$ & $\begin{array}{l}24(92) \\
2(8)\end{array}$ & 0.083 \\
\hline Histology grading, $\mathrm{n}(\%)$ & $\begin{array}{l}\text { G1-2 } \\
\text { G3-4 }\end{array}$ & $\begin{array}{l}56(60) \\
38(40)\end{array}$ & $\begin{array}{l}45(62) \\
28(38)\end{array}$ & $\begin{array}{l}11(52) \\
10(48)\end{array}$ & 0.446 \\
\hline Histology type, n (\%) & $\begin{array}{l}\text { Squamous } \\
\text { Basaloid }\end{array}$ & $\begin{array}{l}93(80) \\
29(20)\end{array}$ & $\begin{array}{l}74(77) \\
22(23)\end{array}$ & $\begin{array}{l}19(73) \\
7(37)\end{array}$ & 0.670 \\
\hline Clinical stage, n (\%) & $\begin{array}{l}\text { I } \\
\text { II } \\
\text { III }\end{array}$ & $\begin{array}{l}20(16) \\
36(30) \\
66(54)\end{array}$ & $\begin{array}{l}11(12) \\
31(32) \\
54(56)\end{array}$ & $\begin{array}{c}8(31) \\
6(23) \\
12(46)\end{array}$ & 0.053 \\
\hline T stage, $\mathrm{n}(\%)$ & $\begin{array}{l}\mathrm{T} 1-\mathrm{T} 2 \\
\mathrm{~T} 3-\mathrm{T} 4\end{array}$ & $\begin{array}{l}73(60) \\
49(40)\end{array}$ & $\begin{array}{l}55(57) \\
41(43)\end{array}$ & $\begin{array}{l}18(69) \\
8(31)\end{array}$ & 0.271 \\
\hline N stage, n (\%) & $\begin{array}{l}\text { N0 } \\
\text { N1 }\end{array}$ & $\begin{array}{l}63(52) \\
59(48)\end{array}$ & $\begin{array}{l}48(50) \\
48(50)\end{array}$ & $\begin{array}{l}15(58) \\
11(42)\end{array}$ & 0.486 \\
\hline Pre-treatment SCCA oncomarker elevation, n (\%) & $\begin{array}{l}\text { Yes } \\
\text { No }\end{array}$ & $\begin{array}{l}20(53) \\
18(47)\end{array}$ & $\begin{array}{r}5(33) \\
10(67)\end{array}$ & $\begin{array}{l}15(65) \\
8(35)\end{array}$ & 0.054 \\
\hline Chemotherapy, n (\%) & $\begin{array}{l}\text { Yes } \\
\text { No }\end{array}$ & $\begin{array}{l}89(73) \\
33(27)\end{array}$ & $\begin{array}{l}72(75) \\
24(25)\end{array}$ & $\begin{array}{l}17(65) \\
9(35)\end{array}$ & 0.328 \\
\hline Smoking history, n (\%) & $\begin{array}{l}\text { Non-smoker } \\
\text { Stop smokers } \\
\text { Smokers }\end{array}$ & $\begin{array}{l}40(48) \\
9(11) \\
35(41)\end{array}$ & $\begin{array}{c}28(49) \\
7(10) \\
33(41)\end{array}$ & $\begin{array}{l}12(76) \\
2(12) \\
2(12)\end{array}$ & 0.027 \\
\hline RT technique & $\begin{array}{l}\text { 3D-CRT } \\
\text { IMRT }\end{array}$ & $\begin{array}{l}84(69) \\
38(31)\end{array}$ & $\begin{array}{l}82(85) \\
14(15)\end{array}$ & $\begin{array}{c}2(8) \\
24(92)\end{array}$ & $<0.001$ \\
\hline Time since diagnosis to treatment (range), days & & $62(17-156)$ & $64(17-129)$ & $59(30-156)$ & 0.487 \\
\hline Overall RT treatment time (range), days & & $57(13-164)$ & $58(13-164)$ & $55(36-70)$ & 0.516 \\
\hline Mean maximum dose (Gy) to primary tumor & & 59.5 & 60 & 58 & 0.106 \\
\hline
\end{tabular}


definition of the primary tumor and lymph node involvement in planning $\mathrm{CT}$.

Treatment. A summary of the treatment protocol is shown in Table 2. Planning CT was performed in a supine position. Delineation of the primary tumor and lymph nodes GTV was facilitated by fusion of planning CT with diagnostic imaging where possible. Only PET/CT negative lymph nodes received elective radiotherapy total dose $30.6-36 \mathrm{~Gy}$ according to RTOG 98-11 trial [2] (including CT-enlarged but FDG-negative inguinal lymph nodes [23] and including all T1-4 N0 stages). The PET/CT positive lymph nodes were treated to radical dose 50-60 Gy according to size, location, and proximity and tolerance of organs at risk. A $10 \mathrm{~mm}$ margin was added to derive clinical target volume (CTV) of the primary tumor. Patients were independently examined by two radiation oncologists to accurately verify the extent of the primary tumor. In a case of uncertainty of tumor extent, a margin of up to $20 \mathrm{~mm}$ was used. For affected lymph nodes, a $5 \mathrm{~mm}$ margin was used for CTV. Planning target volume (PTV) was derived adding a $7 \mathrm{~mm}$ margin to the CTV. Until 2013, patients were treated with 3D conformal techniques. From 2014 onwards, an IMRT technique with simultaneous boost (IMRT-SIB) was used, adhering to target volume delineation guidelines [24]. Patients with treatment position deviation of more than $5 \mathrm{~mm}$ in the first 3 fractions were daily repositioned using image guided RT (IGRT) with $\mathrm{kV}$ portals.

All patients received curative external beam radiotherapy which was combined with concurrent chemotherapy in $73 \%$ of patients (only patients younger than 70 years, WHO performance status $0-1$ and no severe comorbidities). External beam RT was delivered with 6-18 MV photons to a total dose of 30.6-45.0 Gy in 1.8-2.0 Gy fractions. Primary tumor and lymphadenopathy received a boost to a total dose of 55-60 Gy. The boost was delivered with external beam radiotherapy (in 50\%), interstitial brachytherapy (in $41 \%$ ), or combination of both (in 9\%). Brachytherapy was delivered at the end of external beam therapy in patients with tumors affecting less than half of the anal circumference ( 2 x 5 Gy interstitial brachytherapy once a week). The following constraints were used for plan optimization: $98 \%$ of PTV received $\geq 95 \%$ of the prescribed dose; bowel bag was contoured as a peritoneal cavity with dose constraints of V45 Gy $<195 \mathrm{cc}$ and V50 Gy <50 cc. Bladder with constraints of V50 $<50 \%$ and femoral heads V50 was $<5 \%$ [14]. Doses to external genitalia were kept at $\mathrm{D}_{\text {mean }}<35 \mathrm{~Gy}$ in women and $\mathrm{D}_{\text {mean }}<20 \mathrm{~Gy}$ in men. Concurrent chemotherapy consisted of mitomycin C $10 \mathrm{mg} / \mathrm{m}^{2}$ intravenously on day 1 , and 5-fluorouracil $1000 \mathrm{mg} / \mathrm{m}^{2}$ in-day continuous intravenous infusion during weeks 1 and 5 of radiotherapy.

Post-treatment follow-up. Patients were followed up weekly until the resolution of acute post-radiation symptoms. Tumor response was evaluated at 8 and 12 weeks following RT completion. PET/CT scan was performed in stage III disease to assess complete remission (CR) 3 months after curative RT. Patients who achieved CR had a physical exam every 3 months first two years, every 6 months during year 3-5 and once a year thereafter. Anoscopy was performed once a year or at signs of progression. No imaging methods were used in the follow-up of asymptomatic patients. Patients remaining in CR beyond 5 years were referred to primary care practitioners for further follow-up.

Acute and late toxicities were scored using the RTOG toxicity scale. Acute toxicity was defined as appearing during or up to 3 months after the RT completion. Late toxicity was defined as toxicity occurring later than 3 months from the RT completion.

Statistical analysis. The endpoints were local control, disease-free survival, colostomy free survival, and overall survival (OS). The influence of tumor, patient or treatmentrelated factors on survival was investigated.

Loco-regional control (LRC) was defined as the time from the RT start to last clinical follow-up (in patients with remission) or to the date of local progression of the primary tumor or of the regional lymph nodes. Disease-free survival (DFS) was defined as the time from the RT start to the last clinical follow-up, local or distant failure, or death. Overall survival (OS) was defined as the time from the RT start to the last clinical follow-up or death of any cause.

The data were analyzed with statistical software SPSS version 19.0, p-values of less than 0.05 were considered to indicate statistical significance.

Univariate analyses of survival were carried out by the Kaplan-Meier method and the evaluation of differences between the groups was performed with the log-rank test. Univariate Cox proportional hazards regression analyses were performed to calculate HRs and CIs to evaluate the

Table 2. Treatment protocol according to staging procedure and combined treatment modalities.

\begin{tabular}{|c|c|c|c|c|}
\hline TNM stage & Staging method & $\begin{array}{l}\text { Application of concomitant } \\
\text { chemotherapy }\end{array}$ & RT dose to lymph nodes & RT dose to primary tumor \\
\hline \multirow[t]{3}{*}{$\mathrm{T} 1 / 2 / 3 / 4 \mathrm{~N} 0 \mathrm{M} 0$} & PET staging & Yes & $\begin{array}{l}\text { 30.6-36 Gy-45 Gy (according to } \\
\text { RTOG 98-11) [24], pelvic lymph } \\
\text { nodes contouring [12] }\end{array}$ & \multirow{3}{*}{$\begin{array}{l}\text { Total dose } 50-60 \text { Gy } \\
\text { EBRT or BRT (in tumors } \\
\text { affecting less than half of the } \\
\text { anal circumference) } \\
\text { IMRT SIB preferred }\end{array}$} \\
\hline & & No & 45 Gy all pelvic lymph nodes & \\
\hline & Conventional staging (CT/MRI) & No/Yes & 45 Gy all pelvic lymph nodes & \\
\hline $\mathrm{T} 1 / 2 / 3 / 4 \mathrm{~N} 1 \mathrm{M} 0$ & $\begin{array}{l}\text { PET staging/ Conventional } \\
\text { staging }\end{array}$ & $\mathrm{No} / \mathrm{Yes}$ & $\begin{array}{l}45 \mathrm{~Gy} \text { to all pelvic lymph nodes }+ \\
\text { boost to positive LN 10-14.4 Gy }\end{array}$ & $\begin{array}{l}\text { Total dose primary tumor } \\
55-60 \text { Gy } \\
\text { IMRT SIB preferred }\end{array}$ \\
\hline
\end{tabular}


influence of patient, tumor, and treatment characteristics on risk of mortality or recurrence.

A multivariate analysis of survival using prognostic factors with a p-value of less than 0.2 in univariate analyses according to risk factors was performed with the Cox proportionalhazards regression model using a forward stepwise method to define the independent contribution of each prognostic factor. Fisher's exact test was used to evaluate differences in toxicity and risk factors between groups.

\section{Results}

Treatment outcomes. After curative treatment $92 \%$ of patients achieved CR. The median OS was 136 months. The respective OS rates at 2, 5, and 10 years were $83 \%, 69 \%$, and $60 \%$. The respective DFS rates were $76 \%, 73 \%$, and $73 \%$. The respective LRC rates were $91 \%, 90 \%$, and 90\%. Distant metastases developed only within the first 2 years from therapy in $10 \%$ of patients. Colostomy free interval was $89 \%, 86 \%$,

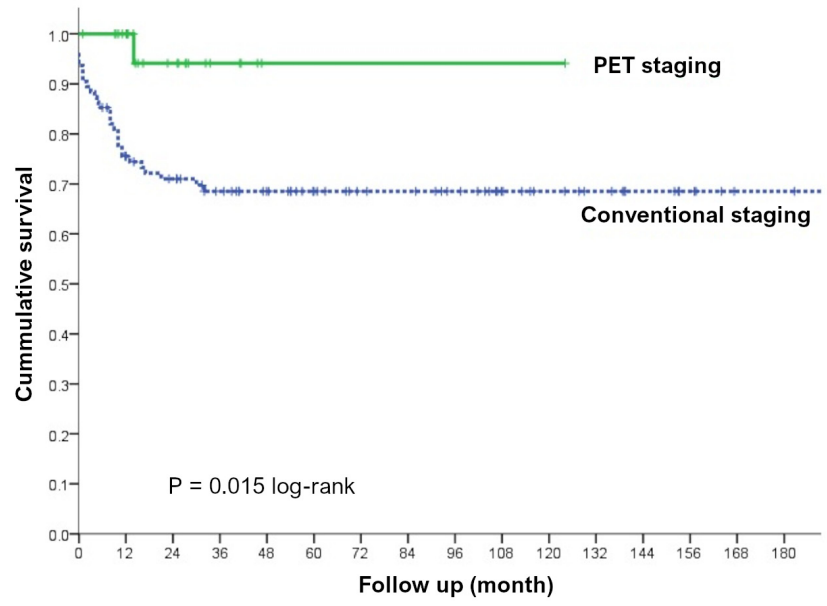

Figure 1. Kaplan-Meier analysis proved statistically significant improvement in disease-free survival with PET staging for all stages.

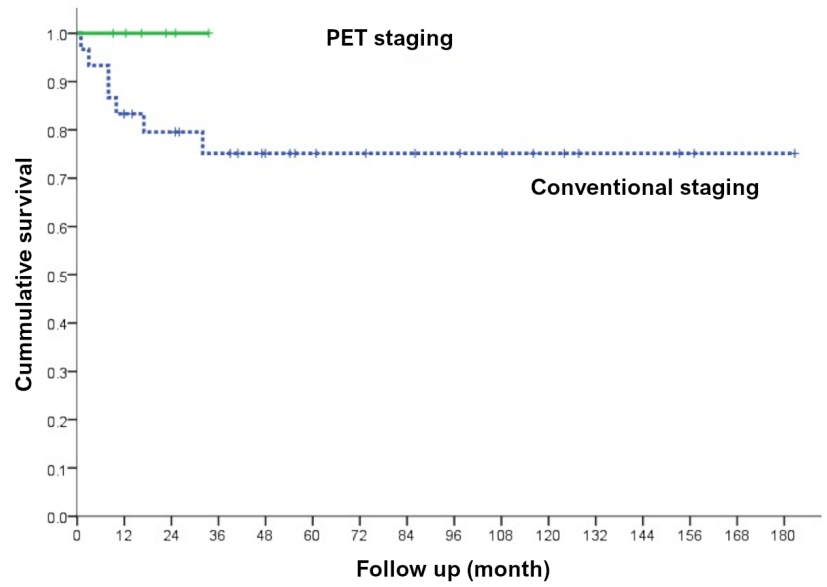

Figure 3. Kaplan-Meier analysis showed significantly improved diseasefree survival with PET staging for stage II. and $81 \%$ at 2,5 , and 10 years, respectively. In all, 16 patients (14\%) ended up needing a colostomy: it was required as a pre-treatment procedure in locally advanced disease in 4 patients, to maintain stool passage in persistent or recurrent disease in 7 patients and to manage late radiotherapy sequelae in 6 patients.

Factors associated with survival. In univariate analysis, significant favorable factors affecting DFS were the use of PET for staging and radiotherapy planning (Figure 1, 2, 3, 4), clinical stage I/II, stage T1/2, and the absence of clinically or radiologically involved lymph nodes (N0).

LRC was associated with T stage and initial WHO performance status in univariate analysis.

There were no significant factors affecting overall survival in univariate analysis and IMRT use had no impact on OS, DFS, or LRC (Table 3).

In multivariate analysis, DFS significantly correlated with PET staging $(\mathrm{p}=0.017$, Table 4$)$. Smoking history and conformal radiotherapy technique were more often present

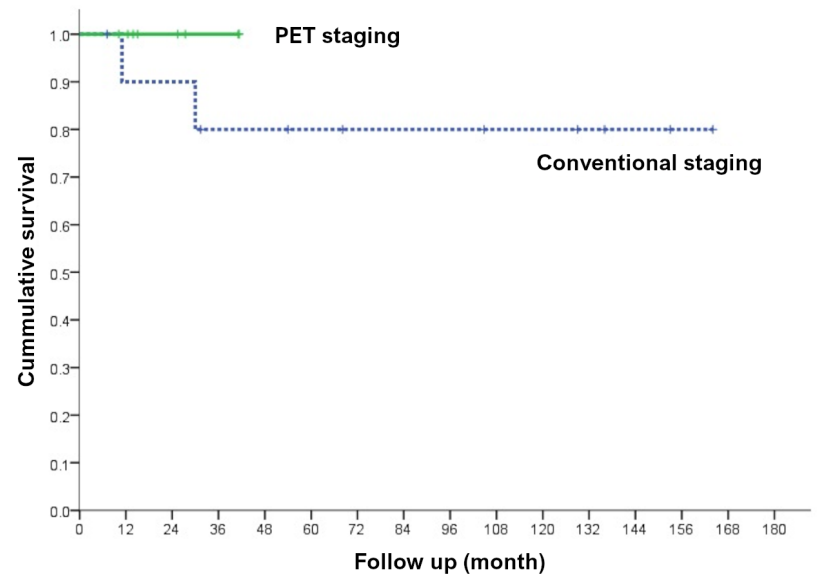

Figure 2. Kaplan-Meier analysis demonstrated improved disease-free survival with PET staging for stage $\mathrm{I}$.

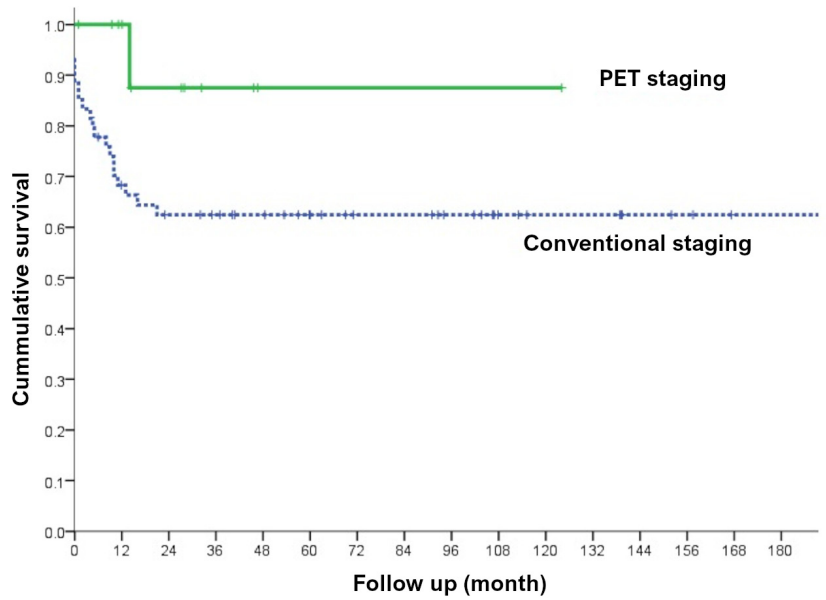

Figure 4. Kaplan-Meier analysis proved significantly improved diseasefree survival with PET staging for stage III. 
Table 3. Univariate Cox proportional hazards regressions analyses for overall survival (OS), loco-regional control (LRC), disease-free survival (DFS).

\begin{tabular}{|c|c|c|c|}
\hline \multirow{2}{*}{ Prognostic factors } & OS & LRC & DFS \\
\hline & HR (95\% CI), p value & HR $(95 \% \mathrm{CI}), \mathrm{p}$ value & HR $(95 \% \mathrm{CI}), \mathrm{p}$ value \\
\hline Gender (F vs M) & $1.458(0.728-2.914), \mathrm{p}=0.286$ & $0.570(0.321-1.012), \mathrm{p}=0.055$ & $0.752(0.502-1.128), \mathrm{p}=0.169$ \\
\hline Age $\leq 60$ vs $>60$ & $1.701(0.911-3.175), \mathrm{p}=0.096$ & $0.614(0.195-1.936), p=0.405$ & $0.652(0.317-1.343), \mathrm{p}=0.246$ \\
\hline Clinical stage (I/II vs III) & $1.026(0.564-1.867), \mathrm{p}=0.933$ & $2,815(0.762-10.406), p=0.121$ & $2.269(1.039-4.955), p=0.040$ \\
\hline $\begin{array}{l}\text { Clinical stage } \\
\text { I vs II } \\
\text { I vs III }\end{array}$ & $\begin{array}{c}1.478(0.535-4.083), \mathrm{p}=0.451 \\
1.361(0.57-3.589), \mathrm{p}=0.533\end{array}$ & $\begin{array}{c}55184.553(0.000-1.2 \mathrm{E} 166, \mathrm{p}=0.954 \\
99067(0.000-2.30 \mathrm{E} 166), \mathrm{p}=0.952\end{array}$ & $\begin{array}{c}1.894(0.393-9.118), \mathrm{p}=0.426 \\
3.441(0.807-14.861), \mathrm{p}=0.095)\end{array}$ \\
\hline $\mathrm{T} 1 / 2$ vs $\mathrm{T} 3 / 4$ & $1.220(0.559-2.257), \mathrm{p}=0.527$ & $4.842(1.310-17.895), p=0.018$ & $3.021(1.437-6.354), p=0.004$ \\
\hline N0 vs N1 (UICC $8^{\text {th }}$ edition) & $1.181(0.649-2.149), \mathrm{p}=0.586$ & $2,275(0.685-7.558), \mathrm{p}=0.180$ & $2.363(1.106-5.050), p=0.026$ \\
\hline Histology grading G1/2 vs G3/4 & $1.210(0.579-2.527), \mathrm{p}=0.612$ & $1.109(0.248-4.957), \mathrm{p}=0.892$ & $1.513(0.655-3.493), \mathrm{p}=0.332$ \\
\hline Histology type (squamous vs basaloid) & $0.790(0.388-1.609), \mathrm{p}=0.517$ & $1.053(0.285-3.891), \mathrm{p}=0.939$ & $0.942(0.419-2.117), \mathrm{p}=0.884$ \\
\hline $\begin{array}{l}\text { WHO performance status } \\
0 \text { vs } 1 \\
0 \text { vs } 2\end{array}$ & $\begin{array}{c}1.697(0.649-4.440), \mathrm{p}=0.281 \\
5.902(0.666-52.291), \mathrm{p}=0.111\end{array}$ & $\begin{array}{c}\mathbf{5 . 8 7 5}(\mathbf{1 . 1 8 5 - 2 9 . 1 2 8}), \mathbf{p}=\mathbf{0 . 0 3 0} \\
0.000(0.000-\mathrm{NS}), \mathrm{p}=0.990\end{array}$ & $\begin{array}{c}2.555(0.951-6.864), \mathrm{p}=0.063 \\
3.476(0.416-29.048), \mathrm{p}=0.250\end{array}$ \\
\hline Pre-treatment SCC oncomarker elevation & $1.289(0.211-7.882), \mathrm{p}=0.784$ & $3.582(0.373-34.577), p=0.268$ & $2.975(0.577-15.342), p=0.193$ \\
\hline Chemo+RT vs RT & $0.608(0.319-1.162), \mathrm{p}=0.132$ & $0.355(0.114-1.102), \mathrm{p}=0.073$ & $0.913(0.406-2.055), \mathrm{p}=0.826$ \\
\hline Smoking history (no vs yes) & $1.017(0.488-2.121), \mathrm{p}=0.964$ & $2.501(0.484-12.921), \mathrm{p}=0.274$ & $0.949(0.385-2.342), \mathrm{p}=0.910$ \\
\hline RT technique (3D-CRT vs IMRT) & $0.473(0.164-1.361), \mathrm{p}=0.165$ & $0.481(0.105-2.202), \mathrm{p}=0.345$ & $0.462(0.176-1.209), \mathrm{p}=0.116$ \\
\hline PET/CT staging vs conventional staging & $0.179(0.024-1.318), \mathrm{p}=0.091$ & $0.034(0.000-14.117), \mathrm{p}=0.272$ & $0.126(0.170-0.927), \mathrm{p}=0.042$ \\
\hline
\end{tabular}

Table 4. Multivariate analyses for overall survival (OS), loco-regional control (LRC), disease-free survival (DFS).

\begin{tabular}{|c|c|c|c|}
\hline \multirow{2}{*}{ Prognostic factors } & OS & LRC & DFS \\
\hline & HR (95\% CI), p value & HR (95\% CI), p value & HR $(95 \% \mathrm{CI}), \mathrm{p}$ value \\
\hline Gender (F vs. M) & n.d. & $\mathrm{p}=0.655$ & n.d. \\
\hline Age $\leq 60$ vs $>60$ & $\mathrm{p}=0.374$ & n.d. & n.d. \\
\hline Clinical stage (I/II vs III) & n.d. & $\mathrm{p}=0.828$ & $\mathrm{p}=0.079$ \\
\hline $\mathrm{T} 1 / 2$ vs $\mathrm{T} 3 / 4$ & n.d. & $\mathrm{p}=0.232$ & $\mathrm{p}=0.068$ \\
\hline N0 vs N1 (UICC $8^{\text {th }}$ edition) & n.d. & $\mathrm{p}=0.792$ & $\mathrm{p}=0.076$ \\
\hline Histology grading G1/2 vs G3/4 & n.d. & n.d. & n.d. \\
\hline Histology type (squamous vs basaloid) & n.d. & n.d. & n.d. \\
\hline $\begin{array}{l}\text { WHO performance status } \\
0 \text { vs } 1\end{array}$ & $\mathrm{p}=0.352$ & $\begin{array}{c}8.101(\mathbf{1 . 5 8 5}-\mathbf{4 1 4 7 6}), \mathbf{p}=\mathbf{0 . 0 1 2} \\
0,000 \text { (not specified) }\end{array}$ & $\mathrm{p}=0.063$ \\
\hline 0 vs 2 & $\mathrm{p}=0.114$ & $\mathrm{p}=0.991$ & $\mathrm{p}=0.427$ \\
\hline Pre-treatment SCC oncomarker elevation & n.d. & n.d. & $\mathrm{p}=0.572$ \\
\hline Chemo+RT vs RT & $\mathrm{p}=0.129$ & $5.164(1.241-21.483), p=0.024$ & n.d. \\
\hline Smoking history (no vs yes) & n.d. & n.d. & n.d. \\
\hline RT technique (3D-CRT vs IMRT) & $\mathrm{p}=0.556$ & n.d. & $\mathrm{p}=0.402$ \\
\hline PET/CT staging vs conventional staging & $\mathrm{p}=0.131$ & n.d. & $13.186(1.578-110.164), p=0.017$ \\
\hline
\end{tabular}

in the conventional staging group, but it influenced neither OS, DFS nor LRC.

LRC in multivariate analysis was affected with initial WHO performance status and chemoradiotherapy, while the multivariate analysis revealed no independent prognostic factors for OS (Table 4).

Safety. As expected, acute postradiation reactions occurred more frequently in patients treated with concomitant chemotherapy. Grade 3/4 leukopenia occurred in 10\% and grade $3 / 4$ gastrointestinal toxicity in $8 \%$ of patients in the chemoradiation group. One patient (1.1\%) died of febrile neutropenia. Grade 3/4 skin toxicity appeared in 55\% of patients with no difference between the chemoradiation and radiation-only subgroups. No other grade 3-5 toxicity appeared in the radiotherapy-only subgroup. There was no grade $\geq 3$ acute genitourinary toxicity.

Late gastrointestinal toxicity grade $3 / 4$ occurred in $7.6 \%$ and late genitourinary toxicity grade $3 / 4$ in $10.4 \%$ of patients.

\section{Discussion}

FDG-PET/CT has been proven to have a significant impact on staging $[16,25]$. PET/CT had superior sensitivity for regional node staging compared to conventional imaging 
( $89 \%$ vs $62 \%$ ) and led to changed treatment management in $16 \%$ of cases [17]. Similarly, the sensitivity of FDG-PET/CT resulted in modified RT treatment plans in 12.5 to $59.3 \%$ of patients $[17,19,26]$. Lower stages were influenced less than locally advanced disease (23\% of T2 and $40 \%$ of T3/4) [17]. The specificity of PET/CT, as assessed by fine needle aspiration (FNA) biopsy, was $83 \%$. The positive predictive value was $43 \%$ [27] suggesting overestimation of lymph node positivity in some cases. However, negative FNA might not conclusively rule out subclinical disease and comparative studies between FNA and pelvic lymphadenectomy are lacking. The above results have been recently corroborated by a study showing the superiority of sentinel lymph node biopsy over PET/CT in predicting survival [28]. An emerging application of CT/PET in anal cancer is the use of nonconventional PET parameters that show better prognostic potential than standardized uptake values [29].

The impact of PET integration into the radiotherapy planning on survival has not been evaluated yet. Complete response on PET/CT appeared to be a good prognostic factor for OS and PFS [26]. The recommended interval from RT to response evaluation was at least 3 months [30].

In our study, all patients received increased radiation dose to metabolically active lymph nodes. At the same time, information from PET/CT allowed reduction of dose to regional not affected lymph nodes areas in N0 disease (including CT-enlarged but FDG-negative inguinal lymph nodes [23] and including all T1-4 stages). We achieved better treatment outcome measures (5-year DFS, LC, and colostomy free interval: $73 \%, 90 \%$, and $86 \%$ ) than reported in RTOG 9811 (5-year DFS, LC, and CFI: 68\%, 80\%, and 72\%) and RTOG 0529 trials (5-year DFS, LC, and CFI: 68\%, 84\%, and $74 \%$ ), which could be explained with inclusion of stage I tumor (not included in RTOG 0529) and through exact radiotherapy treatment planning and lymph nodes dose distribution according to tumor extent. The p16 positivity of all tumors in our series could provide another explanation as such phenotype has been linked to better prognosis [31]. We found that staging PET/CT improves significantly DFS but not LRC, strongly suggesting that the improvement is due to decreased risk of distant metastases after precise pelvic radiotherapy with the increased dose to affected PET/ CT positive lymph nodes.

Limitations of the present study include a non-randomized, retrospective design and the use of historical controls. The time-based identification of cohorts could have been associated with several confounders impacting outcomes, including improved management of toxicities, advances in radiotherapy techniques, and incremental experience gained by the treating team.

In conclusion, $\mathrm{PET} / \mathrm{CT}$ is an important staging tool in squamous cell anal cancer and significantly improves DFS by improving the accuracy of nodal disease extent, which allowed tailored adjustment of RT dose to regional lymph nodes without detriment to LRC. These results suggest a role for PET/CT not only in routine staging but especially in RT planning in patients with localized and locally advanced squamous cell anal cancer.

\section{References}

[1] ISLAMI F, FERLAY J, LORTET-TIEULENT J, BRAY F, JEMAL A. International trends in anal cancer incidence rates. Int J Epidemiol 2017; 46: 924-938. https://doi.org/10.1093/ ije/dyw276

[2] AJANI JA, WINTER KA, GUNDERSON LL, PEDERSEN J, BENSON AB $3^{\mathrm{RD}}$ et al. Fluorouracil, mitomycin, and radiotherapy vs fluorouracil, cisplatin, and radiotherapy for carcinoma of the anal canal: a randomized controlled trial. JAMA 2008; 299: 1914-1921. https://doi.org/10.1001/ jama.299.16.1914

[3] JAMES RD, GLYNNE-JONES R, MEADOWS HM, CUNNINGHAM D, MYINT AS et al. Mitomycin or cisplatin chemoradiation with or without maintenance chemotherapy for treatment of squamous-cell carcinoma of the anus (ACT II): a randomised, phase 3, open-label, $2 \times 2$ factorial trial. Lancet Oncol 2013; 14: 516-524. https://doi.org/10.1016/ S1470-2045(13)70086-X

[4] PEIFFERT D, TOURNIER-RANGEARD L, GERARD JP, LEMANSKI C, FRANÇOIS E et al. Induction chemotherapy and dose intensification of the radiation boost in locally advanced anal canal carcinoma: final analysis of the randomized UNICANCER ACCORD 03 trial. J Clin Oncol 2012; 30: 1941-1948. https://doi.org/10.1200/JCO.2011.35.4837

[5] BARTELINK H, ROELOFSEN F, ESCHWEGE F, ROUGIER P, BOSSET JF et al. Concomitant radiotherapy and chemotherapy is superior to radiotherapy alone in the treatment of locally advanced anal cancer: results of a phase III randomized trial of the European Organization for Research and Treatment of Cancer Radiotherapy and Gastro. J Clin Oncol 1997; 15: 2040-2049. https://doi.org/10.1200/ JCO.1997.15.5.2040

[6] FLAM M, JOHN M, PAJAK TF, PETRELLI N, MYERSON $\mathrm{R}$ et al. Role of mitomycin in combination with fluorouracil and radiotherapy, and of salvage chemoradiation in the definitive nonsurgical treatment of epidermoid carcinoma of the anal canal: results of a phase III randomized intergroup study. J Clin Oncol 1996; 14: 2527-2539. https://doi. org/10.1200/JCO.1996.14.9.2527.

[7] BENSON AB, VENOOK AP, AL-HAWARY MM, CEDERQUIST L, CHEN YJ et al. Anal Carcinoma, Version 2.2018, NCCN Clinical Practice Guidelines in Oncology. J Natl Compr Canc Netw 2018; 16: 852-871. https://doi. org/10.6004/jnccn.2018.0060

[8] GLYNNE-JONES R, TAN D, HUGHES R, HOSKIN P. Squamous-cell carcinoma of the anus: progress in radiotherapy treatment. Nat Rev Clin Oncol 2016; 13: 447-459. https://doi.org/10.1038/nrclinonc.2015.218

[9] GLYNNE-JONES R, NILSSON PJ, ASCHELE C, GOH V, PEIFFERT D et al. Anal cancer: ESMO-ESSO-ESTRO clinical practice guidelines for diagnosis, treatment and follow-up. Radiother Oncol 2014; 111: 330-339. https://doi. org/10.1016/j.radonc.2014.04.013 
[10] KACHNIC LA, WINTER K, MYERSON RJ, GOODYEAR MD, WILLINS J et al. RTOG 0529: a phase 2 evaluation of dose-painted intensity modulated radiation therapy in combination with 5-fluorouracil and mitomycin- $\mathrm{C}$ for the reduction of acute morbidity in carcinoma of the anal canal. Int J Radiat Oncol Biol Phys 2013; 86: 27-33. https://doi. org/10.1016/j.ijrobp.2012.09.023

[11] VUONG T, KOPEK N, DUCRUET T, PORTELANCE L, FARIA $S$ et al. Conformal therapy improves the therapeutic index of patients with anal canal cancer treated with combined chemotherapy and external beam radiotherapy. Int J Radiat Oncol Biol Phys 2007; 67: 1394-1400. https://doi. org/10.1016/j.ijrobp.2006.11.038

[12] NG M, LEONG T, CHANDER S, CHU J, KNEEBONE A et al. Australasian Gastrointestinal Trials Group (AGITG) contouring atlas and planning guidelines for intensitymodulated radiotherapy in anal cancer. Int J Radiat Oncol Biol Phys 2012; 83: 1455-1462. https://doi.org/10.1016/j. ijrobp.2011.12.058

[13] CIOMBOR KK, ERNST RD, BROWN G. Diagnosis and Diagnostic Imaging of Anal Canal Cancer. Surg Oncol Clin N Am 2017; 26: 45-55. https://doi.org/10.1016/j. soc.2016.07.002

[14] KRENGLI M, MILIA ME, TURRI L, MONES E, BASSI MC et al. FDG-PET/CT imaging for staging and target volume delineation in conformal radiotherapy of anal carcinoma. Radiat Oncol 2010; 5: 10. https://doi.org/10.1186/1748717X-5-10

[15] COTTER SE, GRIGSBY PW, SIEGEL BA, DEHDASHTI F, MALYAPA RS et al. FDG-PET/CT in the evaluation of anal carcinoma. Int J Radiat Oncol Biol Phys 2006; 65: 720-725. https://doi.org/10.1016/j.ijrobp.2006.01.009

[16] TRAUTMANN TG, ZUGER JH. Positron Emission Tomography for pretreatment staging and posttreatment evaluation in cancer of the anal canal. Mol imaging Biol 2005; 7: 309313. https://doi.org/10.1007/s11307-005-0003-6

[17] DE WINTON E, HERIOT AG, NG M, HICKS RJ, HOGG A et al. The impact of 18-fluorodeoxyglucose positron emission tomography on the staging, management and outcome of anal cancer. Br J Cancer 2009; 100: 693-700. https://doi. org/10.1038/sj.bjc.6604897

[18] ANDERSON C, KOSHY M, STALEY C, ESIASHVILI N, GHAVIDEL $S$ et al. PET-CT fusion in radiation management of patients with anorectal tumors. Int J Radiat Oncol Biol Phys 2007; 69: 155-162. https://doi.org/10.1016/j. ijrobp.2007.02.055

[19] NGUYEN BT, JOON DL, KHOO V, QUONG G, CHAO M et al. Assessing the impact of FDG-PET in the management of anal cancer. Radiother Oncol 2008; 87: 376-382. https:// doi.org/10.1016/j.radonc.2008.04.003

[20] SAUTER M, VAVRICKA SR, KEILHOLZ G, HEINRICH $\mathrm{H}$, WINDER $\mathrm{T}$ et al. Surveillance of anal carcinoma after radiochemotherapy: A retrospective analysis of 80 patients. Strahlenther Onkol 2017; 193: 639-647. https://doi. org/10.1007/s00066-017-1159-0
[21] CARDENAS ML, SPENCER CR, MARKOVINA S, DEWEES TA, MAZUR TR et al. Quantitative FDG-PET/CT predicts local recurrence and survival for squamous cell carcinoma of the anus. Adv Radiat Oncol 2017; 2: 281-287. https://doi.org/10.1016/j.adro.2017.04.007

[22] SCHWARZ JK, SIEGEL BA, DEHDASHTI F, MYERSON RJ, FLESHMAN JW et al. Tumor response and survival predicted by post-therapy FDG-PET/CT in anal cancer. Int J Radiat Oncol Biol Phys 2008; 71: 180-186. https://doi. org/10.1016/j.ijrobp.2007.09.005

[23] MAI SK, WELZEL G, HERMANN B, WENZ F, HABERKORN U et al. Can the radiation dose to CT-enlarged but FDG-PET-negative inguinal lymph nodes in anal cancer be reduced? Strahlenther Onkol 2009; 185: 254-259. https:// doi.org/10.1007/s00066-009-1944-5

[24] LEPINOY A, LESCUT N, PUYRAVEAU M, CAUBET M, BOUSTANI J et al. Evaluation of a 36 Gy elective node irradiation dose in anal cancer. Radiother Oncol 2015; 116: 197-201. https://doi.org/10.1016/j.radonc.2015.07.050

[25] JONES M, HRUBY G, SOLOMON M, RUTHERFORD N, MARTIN J. The Role of FDG-PET in the Initial Staging and Response Assessment of Anal Cancer: A Systematic Review and Meta-analysis. Ann Surg Oncol 2015; 22: 3574-3581. https://doi.org/10.1245/s10434-015-4391-9

[26] MAHMUD A, POON R, JONKER D. PET imaging in anal canal cancer: a systematic review and meta-analysis. Br J Radiol 2017; 90: 20170370. https://doi.org/10.1259/ bjr.20170370

[27] MISTRANGELO M, PELOSI E, BELLO M, CASTELLANO I, CASSONI P et al. Comparison of positron emission tomography scanning and sentinel node biopsy in the detection of inguinal node metastases in patients with anal cancer. Int J Radiat Oncol Biol Phys 2010; 77: 73-78. https://doi. org/10.1016/j.ijrobp.2009.04.020

[28] DE NARDI P, GUARNERI G, CANEVARI C, TAMBURINI A, SLIM N et al. Prognostic value of fluorodeoxyglucose positron emission tomography/computed tomography and inguinal sentinel lymph node biopsy in patients with anal cancer. Colorectal Dis 2019; 21: 1017-1024. https://doi. org/10.1111/codi.14691

[29] RUSTEN E, REKSTAD BL, UNDSETH C, KLOTZ D, HERNES E et al. Anal cancer chemoradiotherapy outcome prediction using (18) F-fluorodeoxyglucose positron emission tomography and clinicopathological factors. Br J Radiol 2019; 92: 20181006. https://doi.org/10.1259/bjr.20181006

[30] GOLDMAN KE, WHITE EC, RAO AR, KAPTEIN JS, LIEN WW. Posttreatment FDG-PET-CT response is predictive of tumor progression and survival in anal carcinoma. Pract Radiat Oncol 2016; 6: e149-e154. https://doi.org/10.1016/j. prro.2016.01.004

[31] MARTIN D, BALERMPAS P, WINKELMANN R, RODEL F, RODEL C et al. Anal squamous cell carcinoma - State of the art management and future perspectives. Cancer Treat Rev 2018; 65: 11-21. https://doi.org/10.1016/j.ctrv.2018.02.001 